Check for updates

Cite this: RSC Adv., 2019, 9, 37630

Received 8th September 2019

Accepted 11th November 2019

DOI: $10.1039 / c 9 r a 07199 g$

rsc.li/rsc-advances

\section{Construction of a phosphate-rich polyacrylonitrile fiber surface microenvironment for efficient purification of crystal violet wastewater $\dagger$}

\author{
Gang Xu, (D) *ab Mengcan Jin, ${ }^{\text {ab }}$ Fangjia Wang, ${ }^{a}$ Yusef Kianpoor Kalkhajeh, ${ }^{\text {ab }}$ \\ Qizhong Xiong, ${ }^{\mathrm{ab}}$ Liangliang Zhang, ${ }^{\mathrm{ab}}$ Minli Tao*c and Hongjian Gao*ab
}

\begin{abstract}
Wastewater purification using fibrous adsorbents has received much attention due to their high efficiency, low cost, and recyclability. In this work, phosphate modified polyacrylonitrile fiber (B-PANEAPF) was

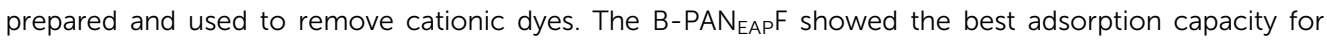
crystal violet (CV) when compared with rhodamine B, methyl green, Victoria blue B, methylene blue, and neutral red. The adsorption tests revealed that the fiber possessed high adsorption efficiency and achieved semi-saturated adsorption within $15 \mathrm{~min}$. The maximum adsorption capacity of $354.46 \mathrm{mg} \mathrm{g}^{-1}$ as calculated by the Langmuir adsorption model was higher than many other adsorbents. Furthermore, the B-PAN efficiency over $90 \%$. Besides, the phosphate functionalized fiber could easily decrease the concentration of $\mathrm{CV}$ to below $0.5 \mathrm{mg} \mathrm{L}{ }^{-1}$ which is below the maximum effluent discharge standard of $15 \mathrm{mg} \mathrm{L}^{-1}$ prescribed in China. It could also be fully recovered and easily separated from the solution to achieve reuse 10 cycles. Moreover, the adsorption mechanism indicated that the adsorption process of the fiber for CV was mainly attributed to electrostatic interaction and hydrogen bonding. In conclusion, the results suggested that the B-PAN $\mathrm{EAP}_{\mathrm{F}}$ characterized by its simplicity, efficiency, eco-friendliness, and reusability, could be a promising candidate for $\mathrm{CV}$ removal.
\end{abstract}

\section{Introduction}

Crystal violet (CV) is widely used as a coloring agent, chromotropic indicator, bacteriostatic agent as well as in food and cosmetics industries. ${ }^{1}$ To date, increasing industrial demand and unreasonable consumption of dyes have become a serious environmental problem threating both human health and ecosystems. ${ }^{2}$ For example, CV contains triphenylmethane with high chemical resistance that can result in kidney failure and vision injuries. ${ }^{3}$ Wastewater containing dyes is also a kind of visual pollution. ${ }^{4}$ Furthermore, cationic dyes are more toxic than anionic ones because they can easily interact with cell membrane surfaces and concentrate in the cytoplasm. ${ }^{5}$ Besides, it is known that about $12 \%$ of the dyes are lost during production and processing, and $20 \%$ of this enters the water environment, ${ }^{6}$ resulting in the waste of resources and

${ }^{a}$ Anhui Province Key Lab of Farmland Ecological Conservation and Pollution Prevention, School of Resource and Environment, Anhui Agricultural University, Hefei, 230036, P. R. China. E-mail: gangxu@ahau.edu.cn; hjgao@ahau.edu.cn

${ }^{b}$ Research Centre of Phosphorous Highly Efficient Utilization and Water Environment Protection, Yangtze River Economic Zone, P. R. China

${ }^{c}$ Department of Chemistry, School of Sciences, Tianjin University, Tianjin, 300072, P. R. China

$\dagger$ Electronic supplementary information (ESI) available. See DOI: 10.1039/c9ra07199g environmental pollution. Hence, it is necessary to develop effective methods for the enrichment, purification, and recovery of $\mathrm{CV}$ in wastewater.

To purify the dyes contaminated water, many techniques such as chemical precipitation, reverse osmosis, membrane filtration, solvent extraction, photocatalytic degradation and adsorption method have been well attempted. ${ }^{7-11}$ Among which, adsorption method becomes one of the most effective methods. ${ }^{12}$ Especially, the introduction of functional groups on the surface of solid supports to prepare novel supported adsorbents has attracted widespread attention for its compelling advantages including low-cost, good stability, simple operation process, and high efficiency. ${ }^{13}$ Recently, various solid supports such as minerals like zeolite, ${ }^{8}$ silica, ${ }^{\mathbf{1 4}}$ carbon materials, ${ }^{\mathbf{1 5}}$ magnetic nanocomposites, ${ }^{\mathbf{1 6}}$ biomass carriers, ${ }^{17}$ and polymers ${ }^{18}$ have been used to remove CV together with fruitful achievements. On the basis of practicality, however, the degree of modification for some supports like minerals is low affecting the removal efficiency. The cost of some nanomaterials is high, and the nanomaterials may also cause secondary pollution in water and soil environments with complex removal operation. These defects inevitably limit their practical applications. Therefore, new supports to fabricate functionalized materials with more excellent absorption ability have received major attention but challenges still remain. 
Organic textile fibers are widely used in people's daily life. Nowadays, the preparation of new functionalized fibers through surface modification is becoming a hot topic in current research. Different functionalized polyacrylonitrile fiber (PANF), polypropylene fiber, cotton fiber $e t c$. are used as emerging class of water pollutant scavenger with many advantages of being easily modifiable and separable, and excellent reusability and environmental friendly properties. ${ }^{19-22}$ Among which, PANF is one of the most promising fibers due to its low-cost, high strength and appropriate hydrophilicity etc. Chemical modification of PANF is simple, which can be modified by conversion of surface functional groups or photochemical grafting. ${ }^{23,24}$ Moreover, PANF is known for its merits for heavy metals' removal. ${ }^{25}$ Until recently, the application of functionalized PANFs to remove organic pollutants in water has gradually drawn people's attention. ${ }^{26-28}$ Our previous work also showed that PANF is an ideal support to prepare novel fiber catalysts ${ }^{29-32}$ and heavy ion colorimetric sensors. ${ }^{33}$ It is found that the modification of the fiber is a deep-seated with high-density modification to construct the specific fiber surface microenvironment constituted by fiber polymer block and modified functional molecules. ${ }^{29}$ More distinctively, the special microenvironment is proved to enrich organic compound impressively in aqueous solution. ${ }^{31,34}$ Inspired by these findings, the functionalized fiber may show better removal capacity for dye in water than traditional adsorption materials. It is worth mentioning that the use of PANF in organic dye removal has been very rare ${ }^{35,36}$ especially no functionalized PANF has been reported for the removal of CV. Hence, it is necessary to use new functionalized PANFs for the removal of CV.

Anionic groups such as carboxylic ion, sulfonate anion, and phenoxy anion have been proved to be effective ways for removing cations dyes. ${ }^{37-39}$ However, the purification of cationic dyes by phosphate has been rarely reported. ${ }^{40}$ Phosphorus compounds containing Brønsted acidic (P-OH) and Lewis basic $(\mathrm{P}=\mathrm{O})$ sites are powerful groups characterized by their stability, high efficiency, and eco-friendliness. Various phosphorus compounds functionalized SBA-15, carbon fibers, and nano diamond have been reported and made important progresses in catalytic, adsorption of metal ions, and electrochemistry. ${ }^{41-43}$ In this work, phosphate functionalized polyacrylonitrile fiber $\left(\mathrm{B}-\mathrm{PAN} \mathrm{EAP}_{\mathrm{EA}} \mathrm{F}\right)$ is prepared by chemical grafting via stable covalent bond. The anionic surface microenvironment is formed on the surface of the fibers which would interact well with cationic dyes. The B-PAN $\mathrm{EAP}_{\mathrm{E}} \mathrm{F}$ was first used to remove cationic dyes. It is easy to modify the fiber with high density, which is beneficial to improve its adsorption performance. In addition, the simple preparation method, economical raw materials and excellent reusability and recyclability of the functionalized fiber make it have high potential in dye purification. The present study tested the adsorption performance of phosphate functionalized fiber for cationic dyes a (Fig. 1). And the adsorption behaviors such as temperature effect, time behavior, reusability and adsorption mechanism etc of the B-PAN $\mathrm{EAP}_{\mathrm{EP}} \mathrm{F}$ for $\mathrm{CV}$ were studied in details.

\section{Materials and methods}

\subsection{Reagents and instruments}

The details of reagents and instruments can be seen in the Section 1 of ESI. $\dagger$

\subsection{The synthesis of B-PAN $\mathrm{EAP}_{\mathrm{F}}$}

The preparation of the functionalized fibers is as follows:

Step 1: the hydroxyethylation of PANF.

A mixture of $4.0 \mathrm{~g}$ PANF, $60 \mathrm{~mL}$ of $\mathrm{H}_{2} \mathrm{O}$ and $40 \mathrm{~mL}$ of 2aminoethanol were placed in a three-necked flask $(250 \mathrm{~mL})$. The above reaction mixture was heated to reflux and reacted for 4 hours. After cooling to room temperature, the functionalized fiber was taken out and washed with warm $\mathrm{H}_{2} \mathrm{O}$ repeatedly. Then the prepared hydroxyethylation fiber $\left(\mathrm{PAN}_{\mathrm{EA}} \mathrm{F}\right)$ was put into the oven drying at $60^{\circ} \mathrm{C}$ for $8 \mathrm{~h}$.

Step 2: the phosphorylation of $\mathrm{PAN}_{\mathrm{EA}} \mathrm{F}$.

A mixture of $1.0 \mathrm{~g} \mathrm{PAN}_{\mathrm{EA}} \mathrm{F}, 20 \mathrm{~mL}$ of $\mathrm{CH}_{3} \mathrm{CN}$ and $2 \mathrm{~mL}$ of $\mathrm{POCl}_{3}$ were placed in a three-necked flask the above mixture was heated at $80{ }^{\circ} \mathrm{C}$ for $4 \mathrm{~h}$. After cooling the mixture to room temperature, the fiber was taken out and put into ice water. After the fiber was stirred for one hour, it was filtered out again and washed with warm $\mathrm{H}_{2} \mathrm{O}$ repeatedly, then the fiber was dried at $60{ }^{\circ} \mathrm{C}$ over night to get phosphorylated fiber PAN ${ }_{\mathrm{EAP}} \mathrm{F}$. Then the fiber PAN $\mathrm{EAP}_{\mathrm{EA}} \mathrm{F}$ was treated with $0.1 \mathrm{M} \mathrm{NaOH}$, then it was washed with $\mathrm{H}_{2} \mathrm{O}$ and dried at $60{ }^{\circ} \mathrm{C}$ overnight to obtain the B-PAN ${ }_{\mathrm{EAP}} \mathrm{F}$.

\subsection{Dyes adsorption capacities of B-PAN $\mathrm{EAP}_{\text {F }}$}

First, $10 \mathrm{mg}$ dried fiber was placed in $20 \mathrm{~mL}$ dye solution $(1 \times$ $10^{-3} \mathrm{~mol} \mathrm{~L}^{-1}$ ), the $\mathrm{pH}$ of the different dye solutions were adjusted to 5 . Then the above solution was stirred using electromagnetic stirring for $4 \mathrm{~h}$ at room temperature. Then, the fiber was taken out with tweezers. In this work, the concentrations of dye after adsorption were measured by UV-vis spectrometer, before testing, the $\mathrm{pH}$ of dye solution was adjusted the same as that of standard curve, all adsorption tests were performed in triplicate.

\subsection{Adsorption kinetics and isotherm experiments}

The adsorption kinetics and isotherm experiments were carried out in $50 \mathrm{~mL}$ bottle with screw cap containing $20 \mathrm{~mL} \mathrm{CV} \mathrm{solu-}$ tion $(\mathrm{pH}=6)$ and $10 \mathrm{mg}$ of B-PAN $\mathrm{EAP}_{\mathrm{F}}$. For the kinetics studies,

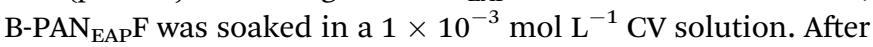
stirring for the desired time, the fiber was filtered out and the CV concentration in the remaining solution was measured by UV-vis spectrometer. In the adsorption isotherm tests, the initial CV concentrations were varied from 0.05 to $1 \mathrm{mmol} \mathrm{L}^{-1}$, the different $\mathrm{CV}$ solution was stirred for $3 \mathrm{~h}$ to guarantee the adsorption equilibrium had reached. Then the concentration of $\mathrm{CV}$ in each solution was measured by UV-vis spectrometer.

\subsection{Desorption test}

Dried fiber $(100 \mathrm{mg})$ was immersed in $20 \mathrm{~mL} \mathrm{CV}$ solution $\left(0.2 \mathrm{mmol} \mathrm{L}^{-1}, \mathrm{pH}=6\right)$. The solution was stirred for $1 \mathrm{~h}$ at room temperature. The fiber was taken out with tweezers and washed with deionized water. Then the $\mathrm{CV}$ adsorbed fiber was put into 
$50 \mathrm{~mL} 0.2 \mathrm{M} \mathrm{HCl}$ solution stirring for $2 \mathrm{~h}$. After desorption, the fiber was taken out and washed with $0.1 \mathrm{M} \mathrm{NaOH}$ solution and deionized water, respectively. Then, it was used for the next circulate. The $\mathrm{CV}$ concentrations after adsorption $\left(C_{\mathrm{e}}\right)$ and desorption $\left(C_{\mathrm{d}}\right)$ were determined by UV. The desorption percentage $D(\%)$ was calculated from: $D=\left(V_{2} \times C_{\mathrm{d}}\right) /\left[V_{1} \times\left(C_{0}-C_{\mathrm{e}}\right)\right] \times 100 \%$, and the removal efficiency was calculated from: $R=\left[\left(C_{0}-C_{\mathrm{e}}\right) / C_{0}\right]$, where $C_{0}$ is the initial concentration of $\mathrm{CV}, V_{1}$ and $V_{2}$ are the volumes of adsorptive solution and eluent solution, respectively.

\subsection{The adsorption of B-PAN $\mathrm{EAP}_{\mathrm{E}}$ for $\mathrm{CV}$ under continuous- flow process}

B-PAN $\mathrm{EAP}_{\mathrm{E}} \mathrm{F}(300 \mathrm{mg}$ ) was filled into a silicone column with length of $100 \mathrm{~mm}$ and inside diameter of $5.6 \mathrm{~mm}$. The flow rate of the continuous-flow device was adjusted to $1 \mathrm{~mL} \mathrm{~min}^{-1}$, then a CV solution $\left(C_{0}=0.2 \mathrm{mmol} \mathrm{L}^{-1}, \mathrm{pH}=6\right)$ was pumped through the silicone column. The receptor liquid was collected in the flask and then the concentration of $\mathrm{CV}$ in the receptor fluid was determined by UV-vis spectrometer.

\section{Results and discussion}

\subsection{The preparation and characterization of the fiber}

3.1.1 The synthesis of phosphate functionalized fiber. Our previous work showed that the $\mathrm{PAN}_{\mathrm{EAP}} \mathrm{F}$ could be effectively modified onto the surface of PANF via a simple two-step strategy (Fig. 1). Furthermore the characterization technologies of elemental analysis, FTIR, XPS, solid-NMR, SEM, XRD, BET, and mechanical properties etc. were used to verify the success of grafting process. $^{31}$ Based on previous research, phosphate functionalized fiber B-PAN $\mathrm{EAP}_{\mathrm{F}} \mathrm{F}$ was easily prepared by alkalization treatment of $\mathrm{PAN}_{\mathrm{EAP}} \mathrm{F}$. The degree of modification of the functionalized fibers were expressed by weight gain and phosphorus content, respectively. As shown in Table 1, the weight gain of the hydroxyethylated fiber $\mathrm{PAN}_{\mathrm{EA}} \mathrm{F}$ (Table 1, entry 2) is $15.7 \%$ based on PANF, and the $\mathrm{OH}$ content of the $\mathrm{PAN}_{\mathrm{EA}} \mathrm{F}$ is calculated as $2.34 \mathrm{mmol} \mathrm{g}^{-1}$ according to the weight gain. For the phosphorylated fiber $\mathrm{PAN}_{\mathrm{EAP}} \mathrm{F}$, the weight gain easily reached to a high level of $18.6 \%$ (Table 1 , entry 3 ), and the $\mathrm{P}$ content measured by ICP-OES and the acid content determined by acid-base titration were $1.72 \mathrm{mmol} \mathrm{g}^{-1}$ and $2.93 \mathrm{mmol} \mathrm{g}^{-1}$, respectively. It is obvious that the modification degree of the fiber is high ( $\left.>1 \mathrm{mmol} \mathrm{g}^{-1}\right)$, which will help to improve its adsorption capacity. The mechanical properties of the fibers were also tested and the results are showed in Table 1 . The breaking strengths of $\mathrm{PAN}_{\mathrm{EAP}} \mathrm{F}$ and $\mathrm{B}-\mathrm{PAN}_{\mathrm{EAP}} \mathrm{F}$ decreased slightly from $11.21 \mathrm{cN}$ to $9.21 \mathrm{cN}$ and $9.03 \mathrm{cN}$ which all kept over $80.5 \%$ strength of the PANF. Overall, the results indicated that the phosphorylated fiber with high degree of modification and excellent strength is a potential adsorbent for water treatment.

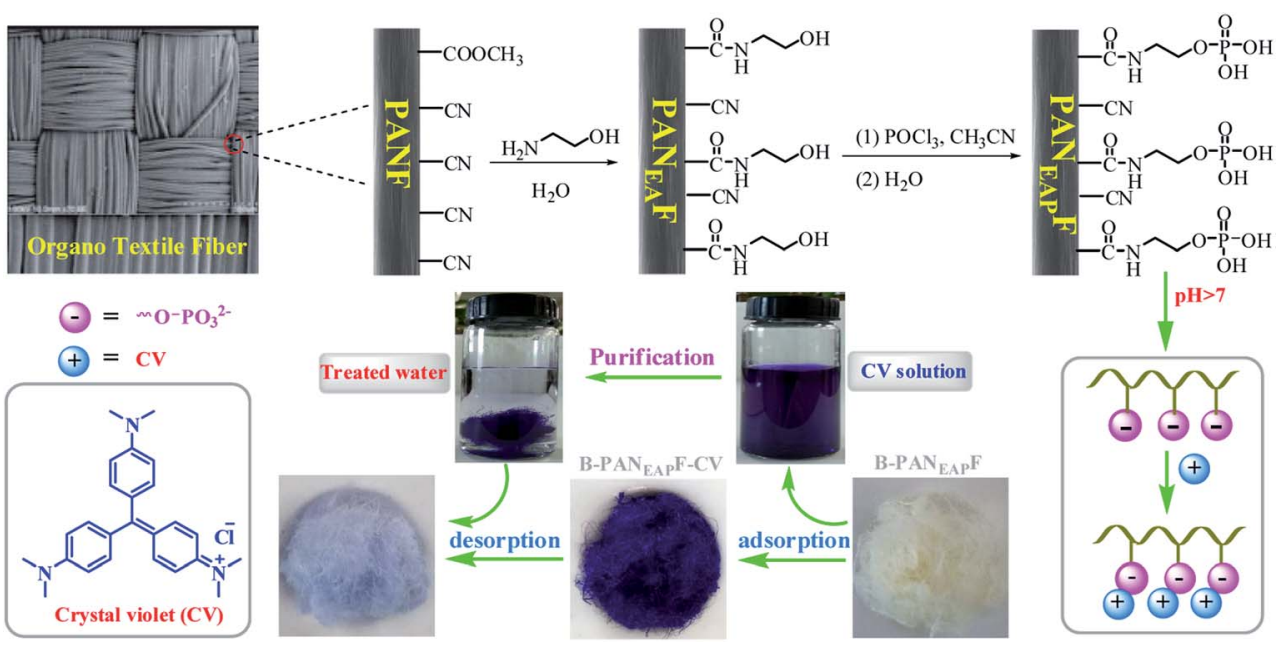

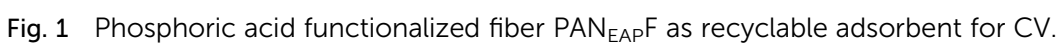

Table 1 The weight gain of functionalized fibers and their P content, acid content, and mechanical properties

Mechanical properties

\begin{tabular}{lllllll} 
Entry & Fiber & Weight gain $^{a}(\%)$ & P content $^{b}\left(\mathrm{mmol} \mathrm{g}^{-1}\right)$ & Acid content $^{c}\left(\mathrm{mmol} \mathrm{g}^{-1}\right)$ & Breaking strength $^{\text {Retention of breaking strength }}$ \\
\hline 1 & PANF & - & 0 & 0 & $11.21 \mathrm{cN}$ & $100 \%$ \\
2 & $\mathrm{PAN}_{\mathrm{EA}} \mathrm{F}$ & 15.7 & 0 & - & $9.94 \mathrm{cN}$ & $88.6 \%$ \\
3 & PAN $_{\mathrm{EAP}} \mathrm{F}$ & 18.6 & 1.72 & 2.93 & $9.21 \mathrm{cN}$ & $82.2 \%$ \\
4 & B-PAN $_{\mathrm{EAP}} \mathrm{F}$ & - & 1.64 & 0 & $9.03 \mathrm{cN}$ & $80.5 \%$
\end{tabular}

${ }^{a}$ Weight gain $=\left[\left(M_{2}-M_{1}\right) / M_{1}\right] \times 100 \%$, where $M_{1}$ and $M_{2}$ are the weights of original fiber and modified fiber. ${ }^{b}$ Determined by ICP-OES.

${ }^{c}$ Determined by acid-base titration. ${ }^{d}$ Based on PANF $=100 \%$. 


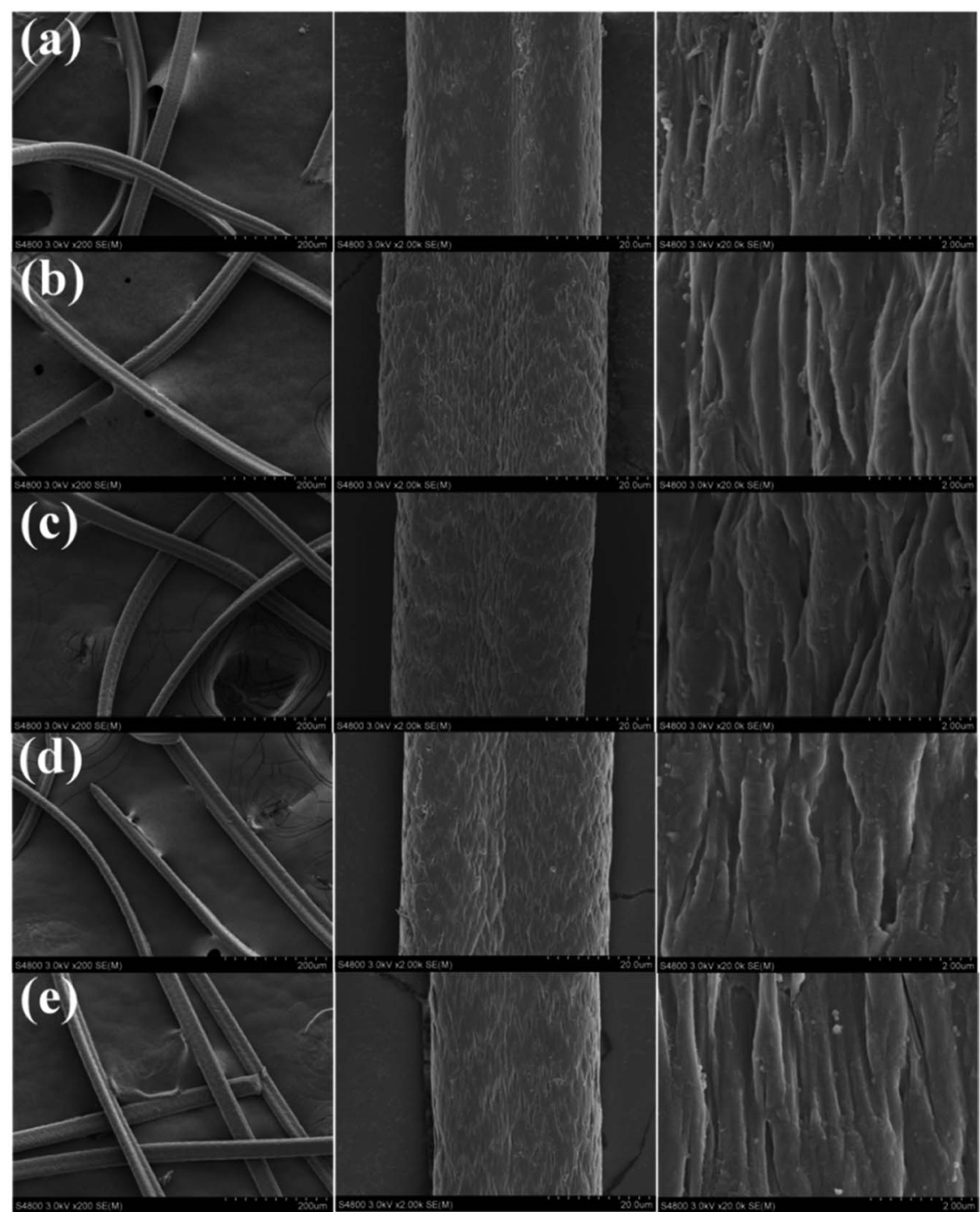

Fig. 2 The SEM images of (a) PAN EAPF, (b) B-PAN EAPF, (c) B-PAN EAPF-CV, (d) B-PAN EAPF-1, (e) B-PAN EAPF-10.

In addition, the specific surface area of the PANF and functionalized fibers are shown in Table S1 $\uparrow$. The fibers contain nanometer sized pores with average pore diameter between 2.2 and $2.8 \mathrm{~nm}$. The specific surface area of B-PAN $\mathrm{EAP}_{\mathrm{EA}} \mathrm{F}$ is $10.2 \mathrm{~m}^{2}$ $\mathrm{g}^{-1}$, the specific surface characteristics of B-PAN ${ }_{\mathrm{EAP}} \mathrm{F}$ may be beneficial to its adsorption capacity.

3.1.2 Surface topography. The SEM images of $\mathrm{PAN}_{\mathrm{EAP}} \mathrm{F}$, B$\mathrm{PAN}_{\text {EAP }} \mathrm{F}, \mathrm{B}-\mathrm{PAN} \mathrm{EAP}_{\mathrm{EA}} \mathrm{F}-\mathrm{CV}$ (CV adsorbed fiber), B-PAN $\mathrm{EAP}_{\mathrm{EP}} \mathrm{F}$ ( one adsorption-desorption cycle), and B-PAN $\mathrm{EAP}_{\mathrm{EA}-10}$ (the tenth adsorption-desorption cycle) are illustrated in Fig. 2. When the images are enlarged 200 times all of the fibers were continuous and showed good integrities, which indicates that the structures of the fibers were well maintained. After the SEM images were magnified to 2000 times, the surface of the $\mathrm{PAN}_{\mathrm{EAP}} \mathrm{F}$ was smooth and uniform (Fig. 2a). After treatment with dilute $\mathrm{NaOH}$, the surface of the B-PAN ${ }_{\mathrm{EAP}} \mathrm{F}$ was not destroyed obviously, just slightly rougher than PAN ${ }_{E A P} F$ (Fig. $2 b$ ). In the SEM image of B-

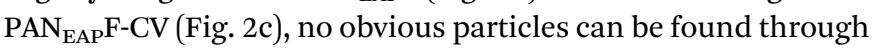
the high magnification (2000 times), and the phenomenon indicated that the $\mathrm{CV}$ dye was adsorbed onto the fiber by chemical interactions rather than simple physical attachment. After ten repetitions (Fig. 2e), the surface of the fiber had no significant changes compared with B-PAN $\mathrm{EAP}_{\mathrm{FA}} \mathrm{F}$ showing the excellent recycling ability of the phosphorylated fiber.

3.1.3 Composition and structure analysis. In this work, the composition and the structure analysis of the B-PAN $\mathrm{EAP}_{\mathrm{EA}} \mathrm{F}$ before and after use were illustrated by elemental analysis, FTIR, ${ }^{13} \mathrm{C}$ solid-state NMR, solid UV-vis, and XRD. Firstly, the elemental analysis data of PANF, B-PAN $\mathrm{EAP}_{\mathrm{EAP}} \mathrm{F}$ and B-PAN $\mathrm{EAP}_{\mathrm{EA}} \mathrm{F}-\mathrm{CV}$ are presented in Table 2 . The nitrogen (17.09\%), carbon (50.87\%) and

Table 2 The elemental analysis data

\begin{tabular}{lllll}
\hline Entry & Sample & C (\%) & H (\%) & N (\%) \\
\hline 1 & PANF & 66.19 & 5.98 & 24.38 \\
2 & B-PAN $_{\text {EAPF }}$ & 50.87 & 5.41 & 17.09 \\
3 & B-PAN $_{\text {EAP }} F-C V$ & 55.59 & 6.19 & 16.95
\end{tabular}


hydrogen $(5.41 \%)$ contents of the B-PAN $\mathrm{EAP}_{\mathrm{E}} \mathrm{F}$ were all decreased due to the modification of new phosphorous-containing functional groups. After adsorption of $\mathrm{CV}$, the carbon (55.59\%) and

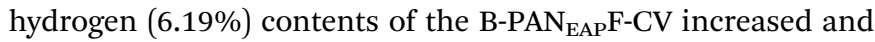
the nitrogen content (16.95\%) decreased as expected. This can be the cause of higher carbon (73.5\%) and hydrogen (7.4\%) contents and lower nitrogen content $(10.3 \%)$ in adsorbed CV molecule. Hence, it is speculated that the $\mathrm{CV}$ was adsorbed on the fiber adsorbent which can also be proved by the fiber photographs before and after adsorption as shown in Fig. S1. $\dagger$ The color change of the B-PAN ${ }_{\mathrm{EAP}} \mathrm{F}$ from light yellow to purplish blue further manifests the success of adsorption process.

The FTIR spectra of the fibers are shown in Fig. 3A and S2. $\dagger$ The FTIR spectra of PANF (Fig. 3A, trace a) showing the absorption peaks at $2242 \mathrm{~cm}^{-1}(\mathrm{C} \equiv \mathrm{N})$ and $1733 \mathrm{~cm}^{-1}(\mathrm{C}=\mathrm{O})$, indicating the existence of the acrylonitrile and methyl acrylate units in the co-polymer of PANF. The wider absorption band of $\mathrm{PAN}_{\mathrm{EA}} \mathrm{F}$ (Fig. 3A, trace b) between 3600 and $3100 \mathrm{~cm}^{-1}$ is attributed to the stretching vibration of the $\mathrm{O}-\mathrm{H}$ and $\mathrm{N}-\mathrm{H}$ groups, and the $\mathrm{C}=\mathrm{O}$ stretching vibration of $\mathrm{PAN}_{\mathrm{EA}} \mathrm{F}$ red shifts from 1733 to $1680 \mathrm{~cm}^{-1}$, which is also due to the formation of amide bonds $(\mathrm{O}=\mathrm{C}-\mathrm{NH})$. After phosphate modification, the absorption peaks at 976,1073 , and $1172 \mathrm{~cm}^{-1}$ of the B-PAN $\mathrm{EAP}_{\mathrm{F}}$ were corresponded to the stretching vibration of $\mathrm{P}-\mathrm{OH}$ and $\mathrm{PO}_{2}$ (ref. 44) suggesting that the phosphate groups were successfully modified in the fiber surface (Fig. 3A, trace c). After adsorption

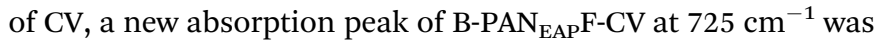
assigned to the out-of-plane bending vibration of phenyl moiety evidencing that the $\mathrm{CV}$ with aromatic structure was successfully adsorbed by B-PAN ${ }_{\mathrm{EAP}} \mathrm{F}$ (Fig. 3A, trace d). Furthermore, when the fiber was reused for 1 and 10 times, the spectra of $B$ $\mathrm{PAN}_{\mathrm{EAP}} \mathrm{F}-1$ and B-PAN $\mathrm{EAP}_{\mathrm{F}}-10$ were almost the same as that of B$\mathrm{PAN}_{\mathrm{EAP}} \mathrm{F}$, indicating that the fiber had high stability and excellent reusability (Fig. 3A, traces e and f). The successful adsorption of $\mathrm{CV}$ can also be demonstrated by ${ }^{13} \mathrm{C}$ solid-state NMR (Fig. 3B). The ${ }^{13} \mathrm{C}$ solid-state NMR of PANF and B-PAN ${ }_{\mathrm{EAP}} \mathrm{F}$ (Fig. 3B, traces a and b) had similar signal peaks at 29.7, 122.1, and $176 \mathrm{ppm}$ which can be assigned to the backbone carbon, ester carbonyl carbon, and cyano group carbon, respectively. ${ }^{45}$

The ${ }^{13} \mathrm{C}$ solid-state NMR spectra of the fibers are shown in Fig. 3B. The spectra of the fibers show signals at 29.7, 122.1 and $176 \mathrm{ppm}$, which are ascribed to backbone carbon, cyano group $(\mathrm{CN})$ and carbonyl $(\mathrm{C}=\mathrm{O})$, respectively. In the ${ }^{13} \mathrm{C}$ solid-state NMR spectrum of B-PAN ${ }_{\mathrm{EAPF}} \mathrm{CV}$ (Fig. 3B, trace c), the new signal peak from $\mathrm{N}\left(\mathrm{CH}_{3}\right)_{2}$ at $45 \mathrm{ppm}$ appeared because the adsorbed $\mathrm{CV}$ contains $\mathrm{N}\left(\mathrm{CH}_{3}\right)_{2}$ groups $^{46}$ in its chemical structure (Fig. 1). The result was further proved by the solid UV-vis

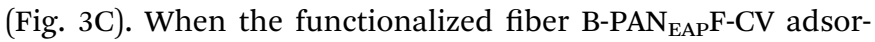
bed $\mathrm{CV}$, its spectrum showed a strong absorption band centered at $595 \mathrm{~nm}$ which is consistent with the maximum UV absorption wavelength of $\mathrm{CV}$ (Fig. S3†). ${ }^{47}$ X-ray powder diffraction (XRD) was used to illustrate the crystalline structure of the fibers (Fig. 3D). In the XRD spectrum of PANF, the sharp diffraction peak at $17^{\circ}$ is the characteristic peaks for (100) crystallographic planes of PANF. ${ }^{48}$ It is obvious that the spectra of B-PAN ${ }_{\mathrm{EAP}} \mathrm{F}, \mathrm{B}-$ PAN $_{\mathrm{EAP}} \mathrm{F}-\mathrm{CV}$, B-PAN $\mathrm{EAP} \mathrm{F}-1$, and $\mathrm{B}-\mathrm{PAN}_{\mathrm{EAP}} \mathrm{F}-10$ were rather
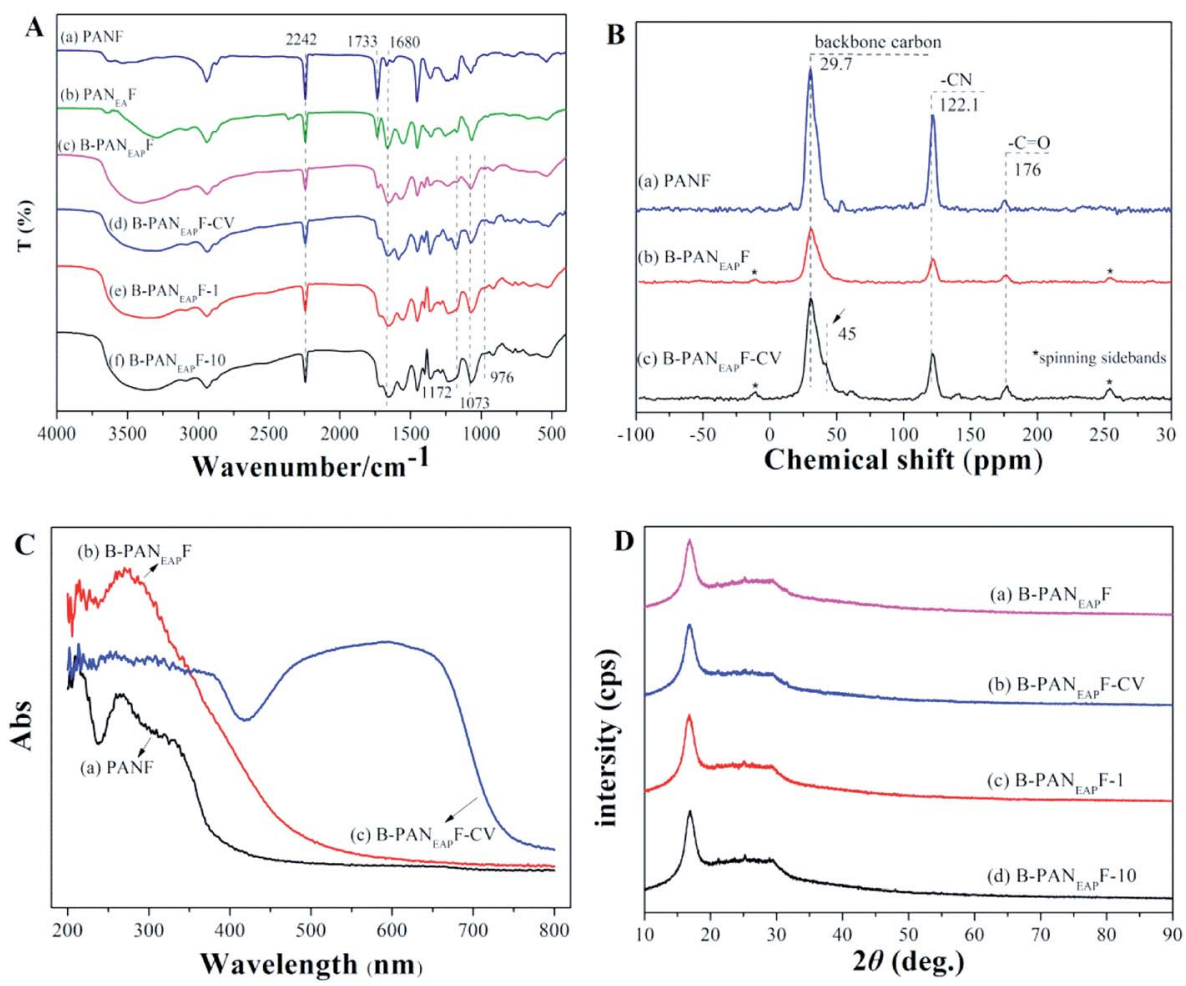

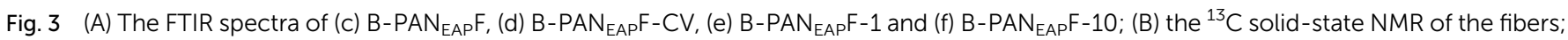

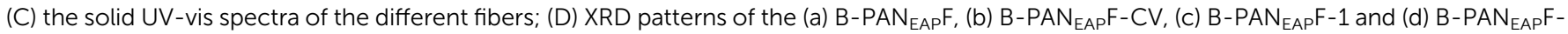
10. 


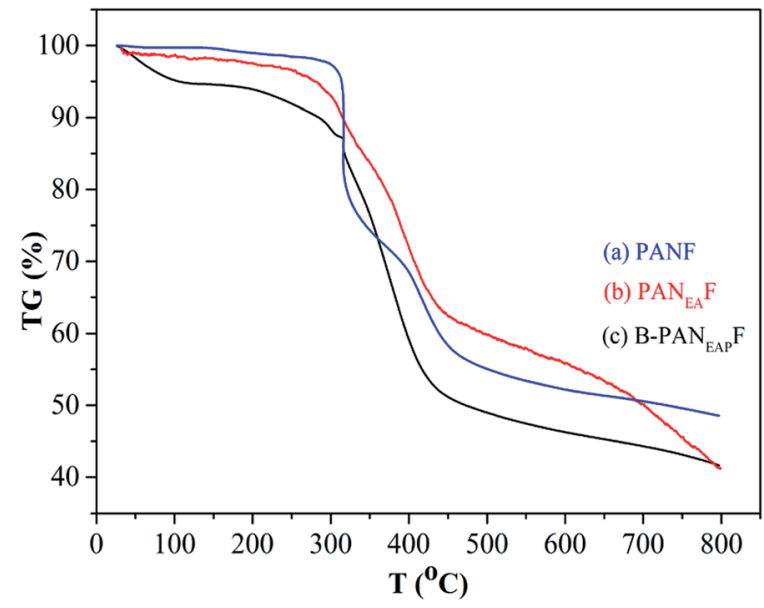

Fig. 4 The thermogravimetric analysis of (a) PANF, (b) PAN $E A F$, and (c) $B-P A N_{E A P} F$.

similar to one of raw PANF (Fig. 3D, traces a-d). This finding suggests that the modification of the fiber mainly occurs in the surface layer of the fiber and it does not destroy the fiber structures. After repeated use, the fiber structure is still well maintained, which is consistent well with the results of SEM and FTIR, showing excellent stability of the functionalized fiber.

3.1.4 Thermal stability analysis. The thermal stability of the fiber within $800{ }^{\circ} \mathrm{C}$ were tested by thermogravimetric analysis in nitrogen atmosphere. As shown in Fig. 4, the weight loss before $100{ }^{\circ} \mathrm{C}$ is mainly caused by water evaporation. It's worth mentioning that there was no significant weight loss before 300 degrees, showing the high thermal stability of the functionalized fibers. The thermal decomposition of fibers were mainly between 300 to $500{ }^{\circ} \mathrm{C}$, and the B-PAN $\mathrm{EAP}_{\mathrm{F}}$ still showed high weight remaining of $40 \%$ at $800{ }^{\circ} \mathrm{C}$, the result indicates that the application of phosphate functional fiber in practical water has high stability.

\subsection{Comparison of adsorption capacities for different dyes by B-PAN EAPF}

The adsorption capacity of the fiber at equilibrium and a given time ( $q_{\mathrm{e}}$ and $q_{t}, \mathrm{mmol}^{-1}$ ) were utilized to evaluate the adsorption performance. The formulas are shown as follows:

$$
\begin{aligned}
& q_{\mathrm{e}}=\frac{\left(C_{0}-C_{\mathrm{e}}\right) \times V}{m} \\
& q_{t}=\frac{\left(C_{0}-C_{t}\right) \times V}{m}
\end{aligned}
$$

where $C_{0}, C_{\mathrm{e}}$ and $C_{t}\left(\mathrm{mmol} \mathrm{L}^{-1}\right)$ are the concentrations at initial, equilibrium and a given time $t(\mathrm{~min})$, respectively, $V$ is the solution volume $(\mathrm{mL})$ and $m$ is the mass of the fiber $(\mathrm{g})$.

Various dyes such as methyl orange, rhodamine B, methyl green, Victoria blue B, methylene blue, neutral red, and crystal violet were used to test the adsorption capacities of the $\mathrm{B}$ $\mathrm{PAN}_{\mathrm{EAP}} \mathrm{F}$. To prevent precipitation, the $\mathrm{pH}$ of all dye solutions was adjusted to 5. The results are shown in Fig. 5, as expected, the B-PAN $\mathrm{EAP}_{\mathrm{E}} \mathrm{Fad}$ almost no affinity for anionic dyes such as

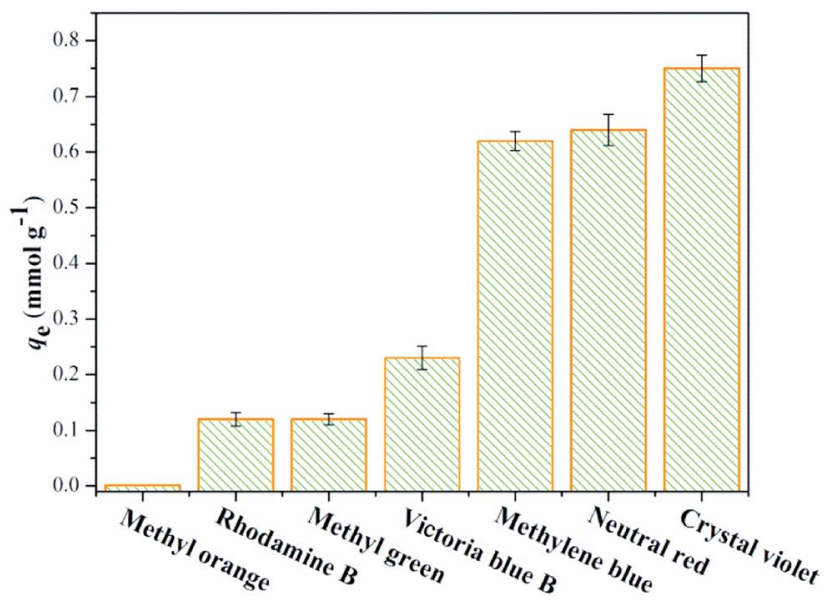

Fig. 5 The adsorption capacities of the B-PAN $\mathrm{EAP}_{\mathrm{F}}$ for different dyes.

methyl orange due to the strong charge repulsion. Nevertheless, the adsorption capacity of B-PAN $\mathrm{EAP}_{\mathrm{F}} \mathrm{F}$ for cationic dyes significantly increased with the highest adsorption capacity of $0.75 \mathrm{mmol} \mathrm{g}^{-1}$ for CV. Furthermore, the B-PAN ${ }_{\mathrm{EAP}} \mathrm{F}$ had higher adsorption capacity for $\mathrm{CV}$, neutral red, and methylene blue than that of rhodamine B, methyl green, and Victoria blue $\mathrm{B}$ (Fig. 5). This is probably due to the large steric hindrance of rhodamine $\mathrm{B}$ and Victoria blue $\mathrm{B}$ that can prevent their adsorption onto the fiber surface, and methyl green containing two positive centers which repel each other and lead to lower removal efficiency than that for CV. Furthermore, the adsorption capacity of neutral red is slightly higher than methylene blue due to the lower steric hindrance. Hence, the above mentioned results show that the B-PAN $\mathrm{EAP}_{\mathrm{EP}} \mathrm{F}$ is an excellent $\mathrm{CV}$ adsorbent. And the $\mathrm{CV}$ is selected as the research object to conduct the following researches.

\subsection{Adsorption performance of the B-PAN $\mathrm{EAP}_{\mathrm{F}}$ for $\mathrm{CV}$}

3.3.1 Effect of $\mathbf{p H}$ on adsorption capacity. It was reported that the solution $\mathrm{pH}$ not only affects the ionization degree of a dye, but also affects the surface charge of a adsorbent. ${ }^{6}$ Therefore, the $\mathrm{CV}$ adsorption by $\mathrm{B}-\mathrm{PAN}_{\mathrm{EAP}} \mathrm{F}$ was studied in details within the $\mathrm{pH}$ ranged from 3 to 9 (Section 2 in $\mathrm{ESI}^{\dagger}$ ). Zero charge $\left(\mathrm{pH}_{\mathrm{PZC}}\right)$ is reported at the $\mathrm{pH}$ in which the initial $\mathrm{pH}$ equals the final $\mathrm{pH}^{41}$ As shown in Fig. 6a, the $\mathrm{pH}_{\mathrm{PZC}}$ of $\mathrm{B}$ $\mathrm{PAN}_{\mathrm{EAP}} \mathrm{F}$ is equal to 7.8. At $\mathrm{pH}<\mathrm{pH}_{\mathrm{PZC}}$, the adsorption capacities of B-PAN $\mathrm{EAP}_{\mathrm{F}}$ increase with the increase of $\mathrm{pH}$ values from 3 to 6 . However, the adsorption capacities had no significant change when the $\mathrm{pH}$ was greater than 6 (Fig. 6b). This might be due to the occurrence of negative charges on the surface of fiber with increasing $\mathrm{pH}$. And the positively charged $\mathrm{CV}$ dye showed a little competition with $\mathrm{H}^{+}$at higher $\mathrm{pH}$ values. Hence, the interaction between anions and cations was more intense resulting in better $\mathrm{B}-\mathrm{PAN}_{\mathrm{EAP}} \mathrm{F}$ removal of $\mathrm{CV}$. In addition, the $\mathrm{p} K_{\mathrm{a}}$ values of the three nitrogen contained functional groups for $\mathrm{CV}$ are $3.29,3.78$ and 4.26 , respectively. ${ }^{47}$ Hence, when the $\mathrm{pH}$ was above $\mathrm{pH}_{\mathrm{PZC}}$, the surface of the fiber was completely deprotonated so that the further increase in $\mathrm{pH}$ had little effect 

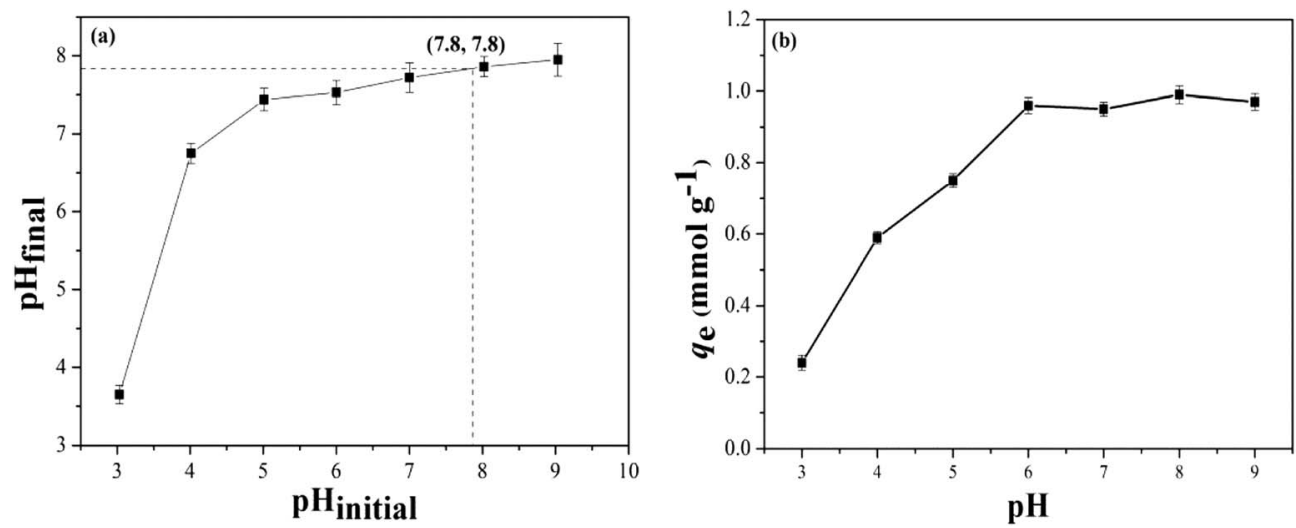

Fig. 6 (a) Relationship between $\mathrm{pH}$ initial and $\mathrm{pH}$ final; (b) the effect of $\mathrm{pH}$ on the adsorption of $\mathrm{CV}$ by B-PAN $\mathrm{EAP}_{\mathrm{F}}$.

on the adsorption of the fiber. This work suggests the pH 6 as the optimal $\mathrm{pH}$ value for future studies.

3.3.2 The determination of the adsorption limit of BPAN $_{\text {EAP }} \mathbf{F}$ for $\mathbf{C V}$. It is very important to reduce residual concentration of the CV solution by adsorbents to safety standard values in real applications. ${ }^{49}$ This work investigated the effect of adsorbent dosage for determination the limit of adsorption (Fig. S4 $\dagger$ ). The initial concentration was as high as $204 \mathrm{mg} \mathrm{L}^{-1}$. An adsorbent dosage of $0.5 \mathrm{~g} \mathrm{~L}^{-1}$, decreased the solution concentration to $30.6 \mathrm{mg} \mathrm{L}^{-1}$. Increasing the adsorbent dosage to $1 \mathrm{~g} \mathrm{~L}^{-1}$ decreased the residual concentrations of the solutions to below $2.3 \mathrm{mg} \mathrm{L}{ }^{-1}$ with high removal efficiencies of above $98 \%$ which were within the wastewater discharge standards of $15 \mathrm{mg} \mathrm{L}^{-1}$ stipulated by China. This is likely due to an increase in adsorption dosage which, in turn, can enhance the specific surface area and the availability of adsorption sites on the fiber surface. ${ }^{50}$ Furthermore, the decrease in the concentration $\mathrm{CV}$ was not obvious with further increase of the dosage. It's worth mentioning that the concentration of the $\mathrm{CV}$ can be reduced to as low as to $0.5 \mathrm{mg} \mathrm{L^{-1 }}$ in the range of this study showing a very low limit of adsorption. A lower dosage of $1 \mathrm{~g} \mathrm{~L}^{-1}$ was observed for fiber adsorbent compared to the biomass combustion residue. ${ }^{51}$ And the former had higher removal efficiency than the reported adsorbents. For example, sawdust and magnetic nanoparticles had lower maximum removal efficiency of $95.58 \%$ and $80.4 \%$, respectively. ${ }^{52,53}$

3.3.3 Adsorption kinetics. Adsorption is a time determined process, the adsorption capacity increases gradually with time until the adsorption equilibrium is reached. The temporal behavior of B-PAN $\mathrm{EAP}_{\mathrm{F}}$ for $\mathrm{CV}$ adsorption was studied and the results are shown in Fig. 7. As presented in Fig. 7a, the adsorption rate began very fast within the first $40 \mathrm{~min}$, and then gradually slowed down as the contact time increased until the adsorption equilibrium was reached. The fiber took about $15 \mathrm{~min}$ to reach over the half saturated adsorption and $60 \mathrm{~min}$ to reach the equilibrium adsorption $\left(0.91 \mathrm{mmol} \mathrm{g}^{-1}\right)$. This is due to the initial existence of free adsorption sites on the B$\mathrm{PAN}_{\mathrm{EAP}} \mathrm{F}$ which can interact with cationic dye CV. With the prolongation of adsorption time, the free adsorption sites of $\mathrm{B}$ $\mathrm{PAN}_{\mathrm{EAP}} \mathrm{F}$ gradually decreased, leading to a lower adsorption rate until equilibrium. The result revealed that the B-PAN ${ }_{\mathrm{EAP}} \mathrm{F}$ can rapidly and efficiently remove $\mathrm{CV}$ from wastewater.

The adsorption process was analysed by different adsorption kinetic models. In this work, the pseudo first-order (3) and pseudo second-order (4) kinetic models were used to gain the rate constant and equilibrium adsorption of $\mathrm{B}-\mathrm{PAN}_{\mathrm{EAP}} \mathrm{F},{ }^{54}$ the $k_{1}$ $\left(\min ^{-1}\right)$ and $k_{2}\left(\mathrm{~g} \mathrm{mmol}^{-1} \mathrm{~min}^{-1}\right)$ are the rate constants.

$$
\log \left(q_{\mathrm{e}}-q_{t}\right)=\log q_{\mathrm{e}}-\left(\frac{k_{1} t}{2.303}\right)
$$
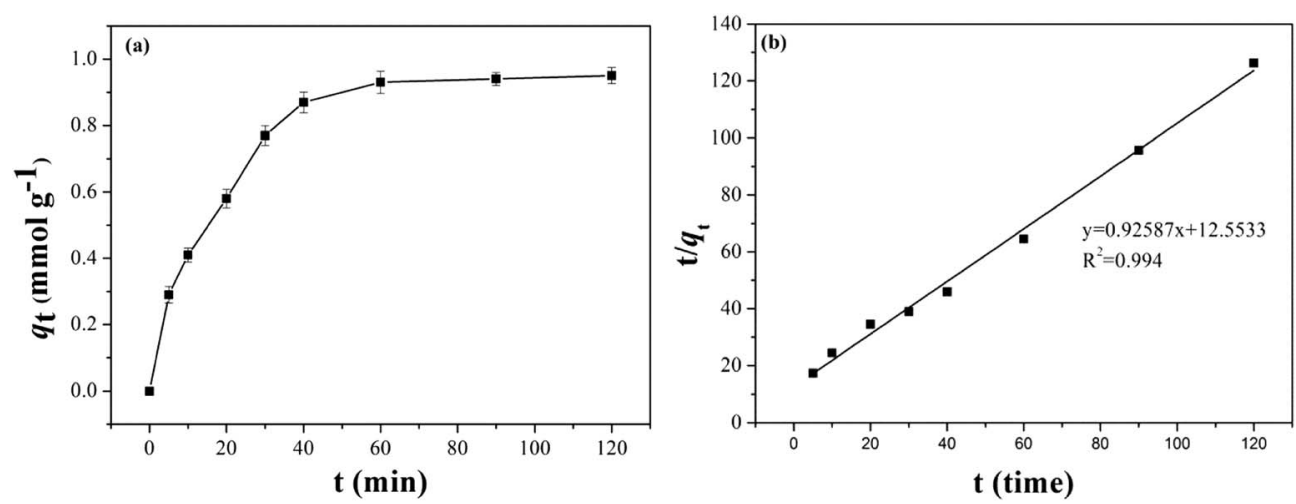

Fig. 7 (a) Equilibrium adsorption capacity of B-PAN $\mathrm{EAP}_{\mathrm{F}}$ at different contact time of CV, (b) pseudo second-order adsorption kinetic. 


$$
\frac{t}{q_{t}}=\frac{1}{k_{2} q_{\mathrm{e}}^{2}}+\frac{t}{q_{\mathrm{e}}}
$$

Previous works have shown that if the adsorption process is more in line with the second-order kinetic model, it is more likely to be a chemical adsorption, while the first-order kinetic model is more inclined to physical adsorption. ${ }^{55}$ The fitting results are shown in Fig. $7 \mathrm{~b}$ and $\mathrm{S} 5, \dagger$ the adsorption kinetics constants are summarized in Table S2. $\uparrow$ The adsorption of CV by B-PAN ${ }_{\text {EAP }} \mathrm{F}$ was more consistent with the pseudo secondorder kinetics model $\left(R^{2}=0.994\right)$ rather than the first-order kinetics model $\left(R^{2}=0.976\right)$ indicating a chemical interaction between $\mathrm{CV}$ and phosphate anion rather a physical interaction.

3.3.4 Adsorption isotherm. The maximum adsorption capacity of adsorbents is affected by the initial concentration. Generally speaking, with the increase of initial concentration, the adsorption capacity of adsorbents increases until the maximum adsorption is achieved. As shown in Fig. 8a, the BPAN $_{\mathrm{EAP}} \mathrm{F}$ could adsorb most of the $\mathrm{CV}$ at a low concentration of CV. Nevertheless, there were many free active sites which could not bind CV resulting in a lower adsorption capacity. Due to the higher driving force for mass transfer, the adsorption capacity of B-PAN ${ }_{\text {EAP }}$ F increased along with increasing CV concentration. The maximum adsorption capacity could reach $0.95 \mathrm{mmol} \mathrm{g}^{-1}$ within the range of experimental concentrations which was higher than zeolite ${ }^{47}\left(0.30 \mathrm{mmol} \mathrm{g}^{-1}\right)$, rice husk ${ }^{6}(0.10 \mathrm{mmol}$ $\left.\mathrm{g}^{-1}\right)$, and $\operatorname{chitosan}^{56}\left(0.19 \mathrm{mmol} \mathrm{g}^{-1}\right)$ etc. functionalized adsorbents.

The adsorption process of $\mathrm{B}-\mathrm{PAN}_{\mathrm{EAP}} \mathrm{F}$ for $\mathrm{CV}$ was further investigated by adsorption isotherm. The data of adsorption isotherm were analyzed by Langmuir ${ }^{57}$ (5) and Freundlich isotherm ${ }^{58}(6)$ models:

$$
\begin{gathered}
\frac{C_{\mathrm{e}}}{q_{\mathrm{e}}}=\frac{C_{\mathrm{e}}}{q_{\max }}+\frac{1}{K_{1} \times q_{\max }} \\
\log q_{\mathrm{e}}=\log K_{\mathrm{f}}-\frac{\log C_{\mathrm{e}}}{n}
\end{gathered}
$$

where $n$ is the heterogeneity factor, $K_{1}$ is the Langmuir adsorption constants $\left(\mathrm{L} \mathrm{mmol}^{-1}\right)$ and $K_{\mathrm{f}}$ is the Freundlich adsorption constant $\left(\mathrm{mmol} \mathrm{g}^{-1}\right)$.
It was reported that Langmuir adsorption isotherm model is more suitable for single-layer adsorption, while Freundlich adsorption model is more inclined to multi-layer adsorption. ${ }^{59}$ The fitting results are shown in Fig. $8 \mathrm{~b}$ and $56, \dagger$ and the isotherm constants are summarized in Table S2. $\uparrow$ The adsorption isotherm date fitted best with the Langmuir adsorption model when the $R^{2}$ values were compared. The results showed that the removal of $\mathrm{CV}$ by $\mathrm{B}-\mathrm{PAN}_{\mathrm{EAP}} \mathrm{F}$ tend to be monolayer adsorption process, it also indicated that the adsorption sites on B-PAN ${ }_{\mathrm{EAP}} \mathrm{F}$ were uniform and energetically identical.

3.3.5 Thermodynamic studies. The thermodynamic studies of B-PAN $\mathrm{EAP}_{\mathrm{F}}$ for $\mathrm{CV}$ was studied at 283, 293, and $303 \mathrm{~K}$. As shown in Fig. $\mathrm{S} 7, \dagger$ increasing trend in CV adsorption capacity with an increase in the temperature indicated the process to be endothermic. The temperature dependence of adsorption is associated with different thermodynamic parameters such as standard enthalpy $\left(\Delta H^{\circ}, \mathrm{kJ} \mathrm{mol}^{-1}\right)$, standard entropy $\left(\Delta S^{\circ}, \mathrm{J}\right.$ $\left.\mathrm{mol}^{-1} \mathrm{~K}^{-1}\right)$, and Gibbs free energy $\left(\Delta G^{\circ}, \mathrm{kJ} \mathrm{mol}^{-1}\right)$ which can be calculated by the following equations: ${ }^{60}$

$$
\begin{gathered}
K_{\mathrm{C}}=\frac{C_{\mathrm{Ae}}}{C_{\mathrm{e}}} \\
\Delta G^{\circ}=-R T \ln K_{\mathrm{C}} \\
\ln K_{\mathrm{C}}=\frac{\Delta S^{\circ}}{R}-\frac{\Delta H^{\circ}}{R T}
\end{gathered}
$$

where $K_{\mathrm{C}}$ is distribution coefficient, $C_{\mathrm{Ae}}$ is the amount of $\mathrm{CV}$ adsorbed on B-PAN ${ }_{\mathrm{EAP}} \mathrm{F}\left(\mathrm{mmol} \mathrm{L}^{-1}\right), R$ is the gas constant $(8.314$ $\mathrm{J} \mathrm{mol}^{-1} \mathrm{~K}^{-1}$ ), $T$ is the temperature $(\mathrm{K})$.

As shown in Table $\mathrm{S} 3, \dagger$ the positive values of $\Delta G^{\circ}$ and $\Delta S^{\circ}$ indicate that the adsorption of $\mathrm{CV}$ on the $\mathrm{B}-\mathrm{PAN}_{\mathrm{EAP}} \mathrm{F}$ is a nonspontaneous and an entropy-driven process. And the positive value of $\Delta H^{\circ}\left(13.90 \mathrm{~kJ} \mathrm{~mol}^{-1}\right)$ for $\mathrm{CV}$ adsorption by B-PAN ${ }_{\mathrm{EAP}} \mathrm{F}$ indicates the endothermic adsorption process, it also shows that chemisorption process is the rate controlling step. ${ }^{61}$ The activation energy $\left(E_{\mathrm{a}}\right)$ is the minimum kinetic energy required by the $\mathrm{CV}$ to react with the active sites on the B-PAN $\mathrm{EAP}_{\mathrm{F}} \mathrm{F}$, which can be obtained by the Arrhenius equation. In general, when the value of $E_{\mathrm{a}}$ is higher than $8 \mathrm{~kJ} \mathrm{~mol}^{-1}$, it can be attributed to a chemisorption. ${ }^{62}$ The $E_{\mathrm{a}}$ value calculated from the slope of the
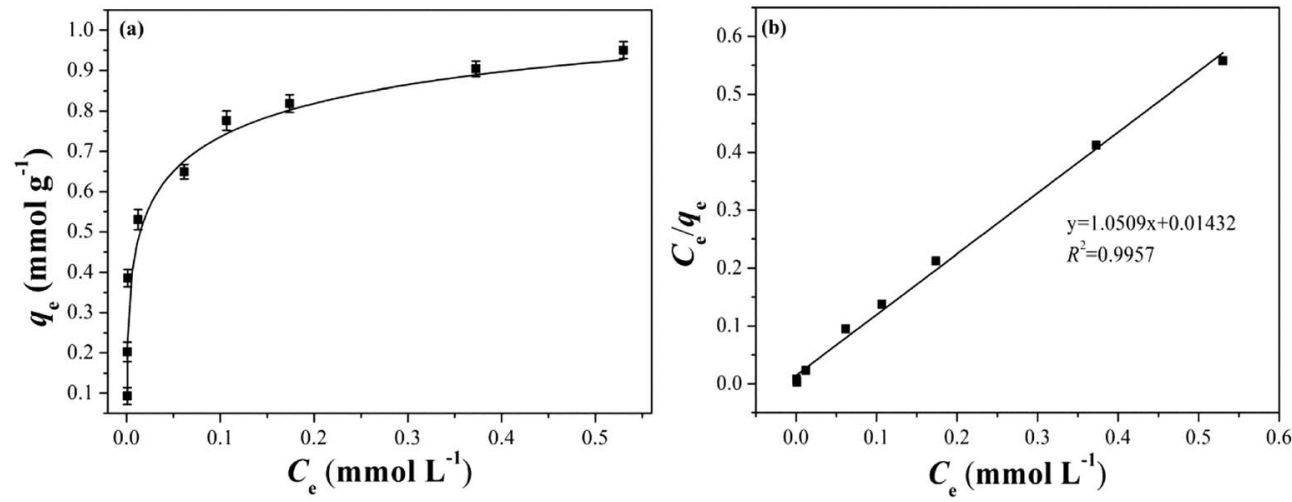

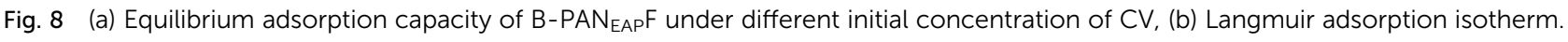



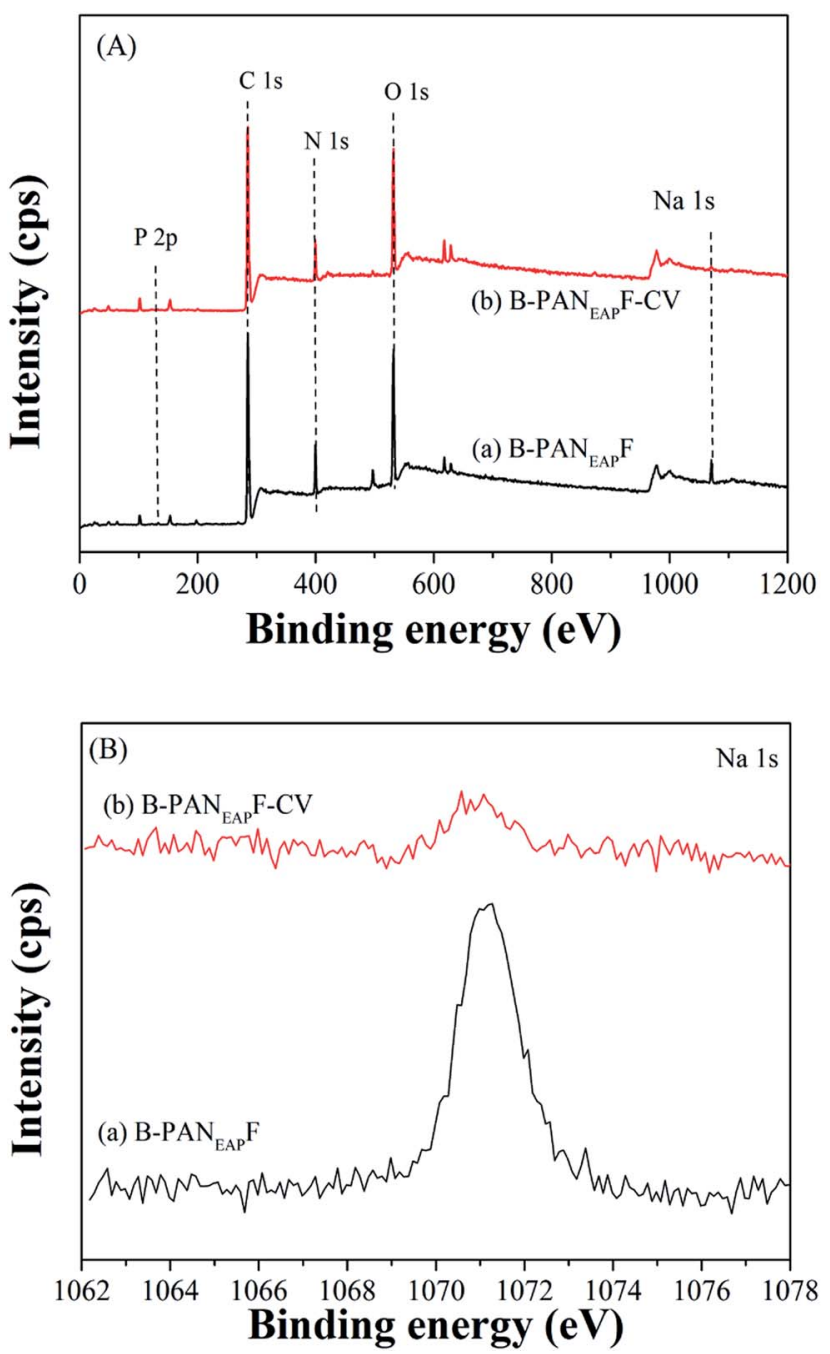

Fig. 9 (A) XPS survey spectrum of (a) B-PANEAPF and (b) B-PAN EAPF$\mathrm{CV}$, (B) high resolution $\mathrm{Na}$ 1s spectra of the fibers.

plot of $\ln k_{2} v s .1 / T$ (Fig. $\mathrm{S} 8 \dagger$ ) is $11.46 \mathrm{~kJ} \mathrm{~mol}^{-1}$, which is consistent with the proposed mechanism of chemisorption.

\subsection{Possible adsorption mechanism of B-PAN $\mathrm{EAP}_{\mathrm{EF}}$ for $\mathrm{CV}$}

According to the above observations, the possible adsorption mechanisms of $\mathrm{B}-\mathrm{PAN}_{\mathrm{EAP}} \mathrm{F}$ for $\mathrm{CV}$ removal were shown in Fig. S9. $\dagger$ It is known that the structure of the adsorbate and the surface properties of the fiber are the most important key points to understand the adsorption mechanism. For instance, CV can dissociate into $\mathrm{CV}^{+}$and $\mathrm{Cl}^{-}$in aqueous solution. ${ }^{6}$ In the literature, the adsorption of cationic dyes by different adsorbents carries out by the electrostatic interaction and hydrogen bonding force. ${ }^{\mathbf{6}, 14,63}$ The fiber adsorbent B-PAN ${ }_{\mathrm{EAP}} \mathrm{F}$ has also similar adsorption forces in the adsorption process. When the $\mathrm{pH}$ value of $\mathrm{CV}$ solution is around the $\mathrm{pHpzc}$ of $\mathrm{B}-\mathrm{PAN}_{\mathrm{EAP}} \mathrm{F}$, the adsorption of $\mathrm{CV}$ by $\mathrm{B}-\mathrm{PAN}_{\mathrm{EAP}} \mathrm{F}$ mainly relies on the strong electrostatic attraction due to the large amounts of anions on the surface of fiber. Additionally, numerous amide amide $\mathrm{N}-\mathrm{H}$ bonds on the surface of fibers are good hydrogen-bonded donors which can interact with tertiary amine $\mathrm{N}$ of $\mathrm{CV}$ through the weak hydrogen bonds interaction. According to the kinetic characteristics of chemical adsorption discussed above, it can be concluded that the adsorption mechanism is mainly chemical interactions between anions and cations, and the interfractional hydrogen bonding force.

In order to further verify the adsorption mechanism of CV by B-PAN ${ }_{\mathrm{EAP}} \mathrm{F}$, the X-ray photoelectron spectroscopy (XPS) of B$\mathrm{PAN}_{\mathrm{EAP}} \mathrm{F}$ before and after the absorption of $\mathrm{CV}$ was tested. The results are shown in Fig. 9 and the corresponding atomic compositions are given in Table S4. $\dagger$ As shown in Fig. 9A, the B-

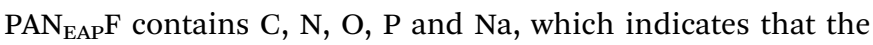
surface layer of the B-PAN $\mathrm{EAP}_{\mathrm{F}} \mathrm{F}$ has sodium phosphate functional groups. Before adsorption of $\mathrm{CV}$, the atomic percent of $\mathrm{Na}$ in $\mathrm{B}-\mathrm{PAN} \mathrm{EAP}_{\mathrm{E}} \mathrm{F}$ is $1.5 \%$ (Table $\mathrm{S} 4, \dagger$ entry 1 ), while the content of sodium atom decreased obviously to $0.5 \%$ after adsorption of $\mathrm{CV}$ (Table S4, $\dagger$ entry 1), the result shows that the $\mathrm{Na}^{+}$on the surface of B-PAN ${ }_{\mathrm{EAP}} \mathrm{F}$ reacts with the $\mathrm{CV}^{+}$in the solution by ion exchange, proving the chemisorption mechanism of B-PAN ${ }_{\mathrm{EAP}} \mathrm{F}$ for $\mathrm{CV}$.

\subsection{Desorption and reusability or the B-PAN ${ }_{E A P} F$}

Recycling ability is an important index for supported adsorbents. It was reported that the cationic dyes could be desorbed from the adsorbents using acid solution. ${ }^{35}$ Inorganic acids such as $\mathrm{HCl}$ have the apparent advantages of low-cost, high efficiency, and environment-friendly properties. Hence, it was selected as the eluent in this study. As shown in Fig. 10, the B$\mathrm{PAN}_{\mathrm{EAP}} \mathrm{F}$ possessed high reusability of more than 10 times with high removal efficiency of above 99\%. The high desorption percentage of over 95\% indicates that most of the adsorbed CV could be desorbed from the fiber surface which also can be proved by the fiber pictures before and after adsorption (Fig. 1). The initial fiber B-PAN $\mathrm{EAP}_{\mathrm{F}}$ was beige, after adsorption of $\mathrm{CV}$ the color of the fiber turned dark blue showing the successful adsorption process. It is worth mentioning that the color of the fiber was very close to the initial fiber after desorption. Furthermore, fiber was fully recovered by the tweezers

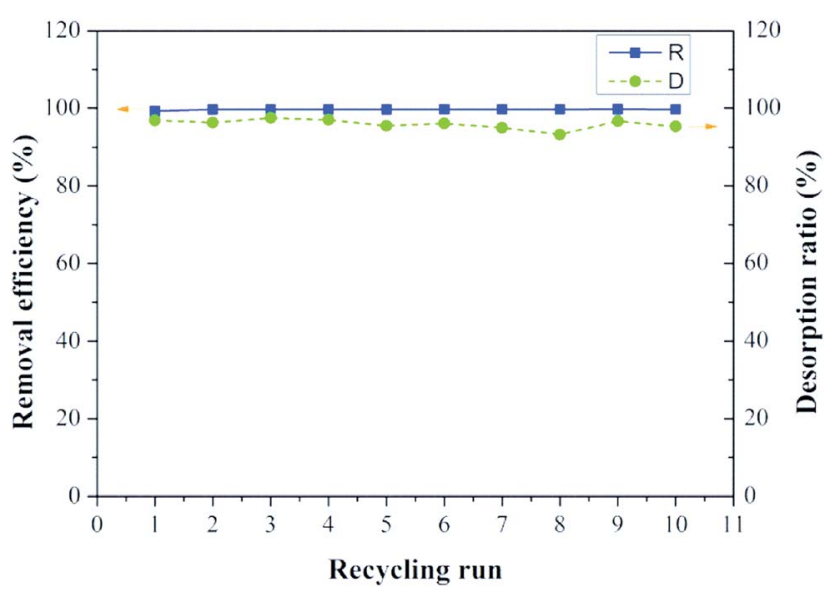

Fig. 10 The recycling ability of B-PAN $\mathrm{EAP}_{\mathrm{F}}$ for CV. 


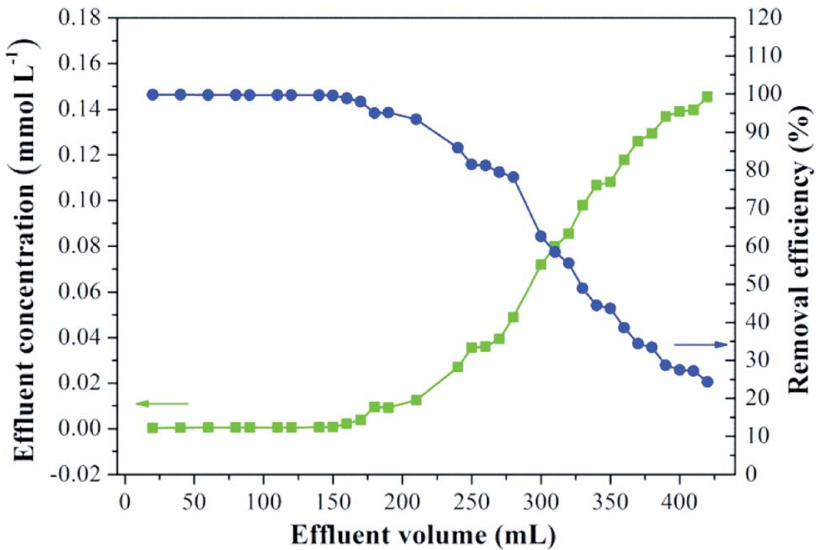

Fig. 11 Breakthrough curves of B-PAN $\mathrm{EAP}_{\mathrm{F}}$ for $\mathrm{CV}$ solution.

possessing irreplaceable advantages over the powder or nanocarrier materials. ${ }^{64}$

\subsection{Use of PAN $\mathrm{EAP}_{\mathrm{EA}} \mathrm{in}$ a flow process}

Functionalized polyacrylonitrile fibers have the characteristic of soft, continuous and easy to knit, which is very suitable for continuous flow application in filled columns. ${ }^{29}$ Our previous work has shown the application potential and merits of the PAN $_{\text {EAP }} F$ in catalytic organic reactions. ${ }^{31}$ For the purpose of practical application, the removal of $\mathrm{CV}$ by $\mathrm{B}-\mathrm{PAN}_{\mathrm{EAP}} \mathrm{F}$ under continuous-flow conditions was studied (Fig. S10†). The breakthrough curve of $\mathrm{B}-\mathrm{PAN}_{\mathrm{EAP}} \mathrm{F}$ for $\mathrm{CV}\left(0.2 \mathrm{mmol} \mathrm{L}^{-1}\right)$ is illustrated in Fig. 11. The concentration of $\mathrm{CV}$ in the column effluent increased with the accumulation of effluent volume. When the volume of effluent does not exceed $210 \mathrm{~mL}$, the removal efficiency of $\mathrm{B}-\mathrm{PAN}_{\mathrm{EAP}} \mathrm{F}$ for $\mathrm{CV}$ was as higher as over $90 \%$. The result show that the continuous flow device is simple and efficient for $\mathrm{CV}$ remediation practically. Therefore, the continuous flow device of fiber can effectively reduce the dye pollution of water body when it is placed at the sewage outfall.

\subsection{Comparison of the adsorption capacities for CV by various supported adsorbents}

Finally, the removal ability for CV of recently used supported adsorbents was compared with the fiber adsorbent presented in this work (Table 3). Firstly, we compared the adsorption capacities of different adsorbents. It is noteworthy that the BPAN $_{\text {EAP }} \mathrm{F}$ exhibited higher removal capacity (354.46 $\mathrm{mg} \mathrm{g}^{-1}$ ) than many mineral, carbon materials, biomass, and metal oxides etc. modified adsorbents. Furthermore, the recyclability of B-PAN $\mathrm{EAP}_{\mathrm{F}} \mathrm{F}$ is better than many other adsorbents. Overall, the many advantages of low-cost, excellent cyclicity and the removal of CV under continuous-flow conditions of the fiber is an attractive approach for practical application.

\section{Conclusion}

In this study, we used polyacrylonitrile fiber, a nontoxic and inexpensive support, to synthesize a phosphate functionalized fiber adsorbent $\mathrm{B}-\mathrm{PAN}_{\mathrm{EAP}} \mathrm{F}$ for the removal of $\mathrm{CV}$. The $\mathrm{B}$ PAN $_{\text {EAP }} \mathrm{F}$ showed higher selectivity and adsorption capacity (354.46 $\mathrm{mg}^{-1}$ ) for CV over many other cationic dyes, viz. rhodamine B, methyl green, Victoria blue B, methylene blue, and neutral red. The adsorption performance tests showed that the residual concentrations of the CV solutions were below $2.3 \mathrm{mg} \mathrm{mL}{ }^{-1}$ with high removal efficiency of $98 \%$ when the adsorption dosage of fiber was as low as $1 \mathrm{~g} \mathrm{~L}^{-1}$. The fiber could also easily decrease the $\mathrm{CV}$ below $0.5 \mathrm{mg} \mathrm{L}^{-1}$ which is substantially lower than $15 \mathrm{mg} \mathrm{L}^{-1}$ maximum effluent discharge standard in China. Furthermore, the B-PAN $\mathrm{EAP}_{\mathrm{E}} \mathrm{F}$ exhibited high adsorption efficiency with semi-saturated adsorption of $15 \mathrm{~min}$. The adsorption data fitted better with the pseudo second-order kinetic and Langmuir adsorption model indicating the monolayer chemisorption between $\mathrm{CV}$ and adsorption sites in the fiber surface. Moreover, the phosphate functionalized fiber can be applied in a continuous-flow system for CV adsorption with high removal efficiency of $90 \%$ when the effluent volume is less than $210 \mathrm{~mL}$. In addition, the fiber can be easily recovered and separated from the solution showing excellent reusability for 10 times. The adsorption mechanisms revealed that the electrostatic interaction between cationic dye and cationic active sites and hydrogen bonding force of amide $\mathrm{N}-\mathrm{H}$ played the key role in adsorption process. In summary, the B-PAN ${ }_{\mathrm{EAP}} \mathrm{F}$ characterized by its simplicity, efficiency, eco-friendliness, and reusability is an attractive adsorbent for $\mathrm{CV}$ removal in wastewater treatment.

Table 3 The removal performances for CV by various supported adsorbents

\begin{tabular}{|c|c|c|c|c|c|c|c|}
\hline Entry & Adsorbent & $\mathrm{pH}$ & $T\left({ }^{\circ} \mathrm{C}\right)$ & Isotherm model & $q_{\max }\left(\mathrm{mg} \mathrm{g}^{-1}\right)$ & Run & Reference \\
\hline 1 & Multi-walled carbon nanotubes & - & - & Langmuir isotherm & 100 & - & 1 \\
\hline 2 & k-Carrageenan- $g$-poly (methacrylic acid) & 7 & 20 & Langmuir isotherm & 28.24 & - & 65 \\
\hline 3 & $\mathrm{NaOH}$-modified rice husk & - & 20 & Langmuir isotherm & 44.87 & - & 6 \\
\hline 4 & ZSM-5 zeolite & 7.5 & 45 & Langmuir isotherm & 141.8 & - & 47 \\
\hline 5 & Montmorillonite, K10 & 5.9 & 30 & Langmuir isotherm & 400 & - & 66 \\
\hline 7 & Modified magnetic nanoadsorbent & 6 & - & Langmuir isotherm & 166.67 & - & 53 \\
\hline 8 & $\mathrm{SiO}_{2} @ \mathrm{MgO}$ & 6.5 & 45 & Langmuir isotherm & 2244.85 & 5 & 64 \\
\hline 10 & Chitosan hydrogel beads & - & 30 & Langmuir isotherm & 76.9 & - & 56 \\
\hline 11 & CarAlg/MMt0.5 & 6.4 & 25 & Langmuir isotherm & 88.8 & - & 67 \\
\hline 12 & $\mathrm{~B}-\mathrm{PAN} \mathrm{EAP}_{\mathrm{E}}$ & 6 & 30 & Langmuir isotherm & 354.46 & 10 & This study \\
\hline
\end{tabular}




\section{Conflicts of interest}

There are no conflicts to declare.

\section{Acknowledgements}

This work was financially supported by the National Natural Science Foundation of China (No. 21777111 and 21572156), the Natural Science Foundation of Anhui Province (No. 1908085QB87), and the Youth Science Fund of Anhui Agricultural University (No. 2018zd05).

\section{References}

1 V. Sabna, S. G. Thampi and S. Chandrakaran, Ecotoxicol. Environ. Saf., 2016, 134, 390-397.

2 I. Ali, C. Peng, D. Lin and I. Naz, in Green Processing and Synthesis, 2019, vol. 8, p. 256.

3 A. Mittal, J. Mittal, A. Malviya, D. Kaur and V. K. Gupta, J. Colloid Interface Sci., 2010, 343, 463-473.

4 W. T. Tsai, C. Y. Chang, C. H. Ing and C. F. Chang, J. Colloid Interface Sci., 2004, 275, 72-78.

5 O. J. Hao, H. Kim and P.-C. Chiang, Crit. Rev. Environ. Sci. Technol., 2000, 30, 449-505.

6 S. Chakraborty, S. Chowdhury and P. Das Saha, Carbohydr. Polym., 2011, 86, 1533-1541.

7 Y.-R. Jiang, H.-P. Lin, W.-H. Chung, Y.-M. Dai, W.-Y. Lin and C.-C. Chen, J. Hazard. Mater., 2015, 283, 787-805.

8 J. L. Marco-Brown, L. Guz, M. S. Olivelli, B. Schampera, R. M. Torres Sánchez, G. Curutchet and R. Candal, Chem. Eng. J., 2018, 333, 495-504.

9 M. G. Peleyeju and O. A. Arotiba, Environ. Sci.: Water Res. Technol., 2018, 4, 1389-1411.

10 I. Ali, C. Peng, I. Naz, Z. M. Khan, M. Sultan, T. Islam and I. A. Abbasi, RSC Adv., 2017, 7, 40158-40178.

11 I. Ali, C. Peng, I. Naz, D. Lin, D. P. Saroj and M. Ali, RSC Adv., 2019, 9, 3625-3646.

12 A. Sharma, Z. Syed, U. Brighu, A. B. Gupta and C. Ram, J. Cleaner Prod., 2019, 220, 23-32.

13 S. Wong, H. H. Tumari, N. Ngadi, N. B. Mohamed, O. Hassan, R. Mat and N. A. Saidina Amin, J. Cleaner Prod., 2019, 206, 394-406.

14 Y. Xiong, J. Chen, M. Duan and S. Fang, Phys. Chem. Chem. Phys., 2018, 20, 19208-19220.

15 S.-S. Yang, Y.-d. Chen, J.-H. Kang, T.-R. Xie, L. He, D.-F. Xing, N.-Q. Ren, S.-H. Ho and W.-M. Wu, J. Cleaner Prod., 2019, 227, 33-47.

16 I. Ali, C. Peng, Z. M. Khan, M. Sultan and I. Naz, Arabian J. Sci. Eng., 2018, 43, 6245-6259.

17 H. Ma, A. Kong, Y. Ji, B. He, Y. Song and J. Li, J. Cleaner Prod., 2019, 214, 89-94.

18 N. Ghaemi and P. Safari, J. Hazard. Mater., 2018, 358, 376388.

19 H. Zhang, D. Fang, Z. Kong, J. Wei, X. Wu, S. Shen, W. Cui and Y. Zhu, Chem. Eng. J., 2018, 331, 406-415.

20 C. Liu, X. Liang, J. a. Liu, Y. Liu, J. Luo and H. Zhu, RSC Adv., 2016, 6, 38430-38436.
21 O. Mapazi, K. P. Matabola, R. M. Moutloali and C. J. Ngila, Polymer, 2018, 149, 106-116.

22 R. Yang, Y. Su, K. B. Aubrecht, X. Wang, H. Ma, R. B. Grubbs, B. S. Hsiao and B. Chu, Polymer, 2015, 60, 9-17.

23 S. Deng, G. Zhang and P. Wang, Environ. Sci.: Water Res. Technol., 2018, 4, 487-492.

24 X.-L. Shi, B. Sun, Y. Chen, Q. Hu, P. Li, Y. Meng and P. Duan, J. Catal., 2019, 372, 321-329.

25 R. Zhao, Y. Li, X. Li, Y. Li, B. Sun, S. Chao and C. Wang, J. Colloid Interface Sci., 2018, 514, 675-685.

26 P. Meng, S. Deng, B. Wang, J. Huang, Y. Wang and G. Yu, Chem. Eng. J., 2017, 315, 108-114.

27 R. Xu, J. Cui, R. Tang, F. Li and B. Zhang, Chem. Eng. J., 2017, 326, 647-655.

28 R. Zhao, Y. Wang, X. Li, B. Sun, Y. Li, H. Ji, J. Qiu and C. Wang, ACS Sustainable Chem. Eng., 2016, 4, 2584-2592.

29 J. Du, G. Xu, H. Lin, G. Wang, M. Tao and W. Zhang, Green Chem., 2016, 18, 2726-2735.

30 J. Cao, P. Li, G. Xu, M. Tao, N. Ma and W. Zhang, Chem. Eng. J., 2018, 349, 456-465.

31 G. Xu, J. Cao, Y. Zhao, L. Zheng, M. Tao and W. Zhang, Chem.-Asian J., 2017, 12, 2565-2575.

32 G. Xu, M. Jin, Y. K. Kalkhajeh, L. Wang, M. Tao and W. Zhang, J. Cleaner Prod., 2019, 231, 77-86.

33 R. Gao, G. Xu, L. Zheng, Y. Xie, M. Tao and W. Zhang, J. Mater. Chem. C, 2016, 4, 5996-6006.

34 G. Xu, L. Wang, M. Li, M. Tao and W. Zhang, Green Chem., 2017, 19, 5818-5830.

35 Y. Fan, H.-J. Liu, Y. Zhang and Y. Chen, J. Hazard. Mater., 2015, 283, 321-328.

36 A. Almasian, M. E. Olya and N. M. Mahmoodi, J. Taiwan Inst. Chem. Eng., 2015, 49, 119-128.

37 Y. Zhang, Y. Ye, X. Zhou, Z. Liu, G. Zhu, D. Li and X. Li, J. Mater. Chem. A, 2016, 4, 838-846.

38 Z. Wang, J. Guo, J. Ma and L. Shao, J. Mater. Chem. A, 2015, 3, 19960-19968.

39 D. Shetty, I. Jahovic, J. Raya, F. Ravaux, M. Jouiad, J.-C. Olsen and A. Trabolsi, J. Mater. Chem. A, 2017, 5, 62-66.

40 I. Ali, C. Peng, T. Ye and I. Naz, RSC Adv. , 2018, 8, 8878-8897. 41 R. Zhao, X. Li, B. Sun, M. Shen, X. Tan, Y. Ding, Z. Jiang and C. Wang, Chem. Eng. J., 2015, 268, 290-299.

42 Q. Gao, J.-F. Xie, Y.-T. Shao, C. Chen, B. Han, K.-S. Xia and C.-G. Zhou, Chem. Eng. J., 2017, 313, 197-206.

43 F. J. García-Mateos, R. Berenguer, M. J. Valero-Romero, J. Rodríguez-Mirasol and T. Cordero, J. Mater. Chem. A, 2018, 6, 1219-1233.

44 T. Y. Ma and S. Z. Qiao, ACS Catal., 2014, 4, 3847-3855.

45 Y. H. Choi, C. M. Choi, D. H. Choi, Y. Paik, B. J. Park, Y. K. Joo and N. J. Kim, J. Membr. Sci., 2011, 371, 84-89.

46 J. Zhang, Y. Wang, N. Luo, Z. Chen, K. Wu and G. Yin, Dalton Trans., 2015, 44, 9847-9859.

47 G. V. Brião, S. L. Jahn, E. L. Foletto and G. L. Dotto, J. Colloid Interface Sci., 2017, 508, 313-322.

48 E. Zussman, X. Chen, W. Ding, L. Calabri, D. A. Dikin, J. P. Quintana and R. S. Ruoff, Carbon, 2005, 43, 2175-2185. 
49 B. C. S. Ferreira, F. S. Teodoro, A. B. Mageste, L. F. Gil, R. P. de Freitas and L. V. A. Gurgel, Ind. Crops Prod., 2015, 65, 521-534.

50 W. Hamza, N. Dammak, H. B. Hadjltaief, M. Eloussaief and M. Benzina, Ecotoxicol. Environ. Saf., 2018, 163, 365-371.

51 S. K. Ghosh and A. Bandyopadhyay, J. Environ. Chem. Eng., 2017, 5, 2415-2430.

52 S. Shakoor and A. Nasar, Groundwater for Sustainable Development, 2018, 7, 30-38.

53 C. Muthukumaran, V. M. Sivakumar and M. Thirumarimurugan, J. Taiwan Inst. Chem. Eng., 2016, 63, 354-362.

54 Y. S. Ho and G. McKay, Process Biochem., 1999, 34, 451-465. 55 L. Bai, H. Hu, W. Zhang, J. Fu, Z. Lu, M. Liu, H. Jiang, L. Zhang, Q. Chen and P. Tan, J. Mater. Chem., 2012, 22, 17293-17301.

56 A. Pal, S. Pan and S. Saha, Chem. Eng. J., 2013, 217, 426-434. 57 I. Langmuir, J. Am. Chem. Soc., 1918, 40, 1361-1402.

58 H. Freundlich, Z. Phys. Chem., Stoechiom. Verwandtschaftsl., 1906, 57, 385-470.
59 N. Uenlue and M. Ersoz, Sep. Purif. Technol., 2007, 52, 461469.

60 A. K. Singha Deb, V. Dwivedi, K. Dasgupta, S. Musharaf Ali and K. T. Shenoy, Chem. Eng. J., 2017, 313, 899-911.

61 C. Xiong, Y. Li, G. Wang, L. Fang, S. Zhou, C. Yao, Q. Chen, X. Zheng, D. Qi, Y. Fu and Y. Zhu, Chem. Eng. J., 2015, 259, 257-265.

62 K. Z. Elwakeel and E. Guibal, Chem. Eng. J., 2015, 281, 345359.

63 A. Masoumi, K. Hemmati and M. Ghaemy, Chemosphere, 2016, 146, 253-262.

64 Y. Pei, M. Wang, D. Tian, X. Xu and L. Yuan, J. Colloid Interface Sci., 2015, 453, 194-201.

65 M. Gholami, M. T. Vardini and G. R. Mahdavinia, Carbohydr. Polym., 2016, 136, 772-781.

66 G. K. Sarma, S. Sen Gupta and K. G. Bhattacharyya, J. Environ. Manage., 2016, 171, 1-10.

67 G. R. Mahdavinia, H. Aghaie, H. Sheykhloie, M. T. Vardini and H. Etemadi, Carbohydrate Polymers, 2013, 98, 358-365. 